Article

\title{
Trust and Positive Working Relationships among Teachers in Communities of Practice as an Avenue for Professional Development
}

\author{
Adeola Folasade Akinyemi ${ }^{1, *(1)}$, Symphorosa Rembe ${ }^{2}$ and Vuyisile Nkonki ${ }^{1}$ \\ 1 Teaching and Learning Centre, University of Fort Hare, Alice 5700, South Africa; vnkonki@ufh.ac.za \\ 2 Faculty of Education, University of Fort Hare, Alice 5700, South Africa; srembe@ufh.ac.za \\ * Correspondence: aakinyemi@ufh.ac.za
}

Received: 11 April 2020; Accepted: 6 May 2020; Published: 12 May 2020

\begin{abstract}
This study explores trust and positive working relationships among teachers in communities of practice as an avenue for professional development in high schools in South Africa. A mixed methods research approach was employed for this study with the use of a semi-structured interview and semi-structured questionnaires as data collection instruments. Ten schools were purposively selected for this study and seventy-nine participants were selected as samples. The findings of the study show that teachers had good working relationships with their colleagues. The good working relationships they had enabled them to assist their colleagues, share their classroom challenges with them, confide in their colleagues, and they were able to get assistance from them. It was established from the study that a great number of teachers feel safe to be part of the communities of practice activities in the sampled high schools, thus, they engage in diverse of discussions with their colleagues and they were able to relate to their colleagues the difficulties they have in terms of their work. The study recommends that teachers should spend an adequate time in their meetings, see themselves as colleagues, interact as teams, and build strong ties to have good relationships and a strong level of trust among themselves.
\end{abstract}

Keywords: professional development; trust; relationship; interaction; participation

\section{Introduction}

Communities of practice are one of the continuing professional teachers' development (CPTD) models. It is a process of coming together by teachers to ascertain their professional requirements and also find means of working together to attain their goals [1]. Teachers need to work as groups and teams in communities of practice, this is important to enable them to develop professionally. This is done through collaboration by all the group members to see how and where to assist each other in areas they need help in terms of their professional development. Thus, communities of practice are seen as an approach for enhancing continuing professional development of teachers in high schools. A lot of studies have shown that if communities of practice are well embraced, teachers in their various school communities see it as a means to share ideas, solve problems, and also relate together in their subject matters [2-5].

In order for communities of practice to exist in high schools, there would be needs for teachers to come together as a group and identify their professional needs and come up with means or ways to achieve those needs. In other words, communities of practice occur amid groups of people who have certain aims and objectives to be achieved. The authors of [6] (p. 7) define communities of practice as individuals who share a concern, a set of problems, or a desire about a subject, and who extend their understanding and proficiency in this area by working together on an on-going basis. This implies 
that in communities of practice, people involved must be able to identify a problem and have a desire for the responsibilities involved and must have a prerequisite knowledge in the areas of concern.

The authors of [7] contend that learning within communities of practice encompasses three indispensable processes, namely:

a. Evolving forms of mutual engagement;

b. Understanding and tuning (their) enterprise;

c. Developing (their) repertoire, styles, and discourses [7] (p. 95).

Mutual engagement amid communities of practice assist members in being familiar with each other and engaging in productive interaction among themselves. This is meant to assist them in building trust among themselves, making them contented in addressing the problems they are facing together, and collaborating with the truth. If there are no strong relationships of belonging, the community might be torn apart. Hence, collaborative learning activities in a community of practice transpires as a result of collaborations amongst members, and not simply as a result of cautious learning events.

The features of communities of practice differ, some communities of practice have designations, while various others do not. Moreover, some communities of practice are rather formal in terms of organisation while others are very fluid and informal [8]. However, no matter the nature of the communities of practice, group members engage as a group by assisting in collective events and things they learnt as a result of their joint commitment and collaborative learning activities. This implies that a community of practice is not the same as a community of importance or an environmental community in that it comprises a collective practice and mutual engagement [7]. This is also relevant in high schools as we have some communities of practice which are informal and they help teachers in areas of professional development through their actions, which boost joint sustenance, group work, and cooperation [9].

Trust and positive working relationships are among the processes established by communities of practice, which is meant to improve teachers' professional development. The authors of [1] state that trust is a vital form of fruitful interactions. When there is no trust amid teachers in communities of practice, there is no likelihood to have a positive working relationship among them. This will surely inhibit learning activities, thus affecting teachers' professional development. The authors of [10] argue that relationships form the threads or the connective tissues of interacted knowledge communities and offer the communal resources that permits teachers to labor collectively over a period of time and surpass what could have been accomplished when working alone.

The authors of [11] affirm that relationships among teachers create a sense of shared responsibility as they relate with one another. They also provide a means of communication and dissemination of information to each other's network activities, as well as help develop a willingness to trust each other. When teachers relate together in communities of practice, they are free with one another and they develop the spirit of trust and are open to discussing their classroom challenges with their colleagues. The authors of [12] also note that relationships allow a network to knit together while the network, in turn, provides the mechanisms to support the relationships.

In professional learning communities, teachers' engagement in learning can be a risky business particularly so if working with their colleagues. Teachers will only open themselves up to learning and participation in learning communities' activities such as classroom observation, discussion about pedagogical issues, and curriculum innovation when they are confident it will be safe for them to do so [13]. Teachers might doubt that their colleagues rely on them by sharing their teaching and learning challenges with the fear that they might use it against them. However, [14] argue that with trust and respect from colleagues, teachers will be free to open up to their colleagues on their teaching and learning challenges.

The authors of [15] argue that trust and positive working relationships can only exist among teachers in professional learning communities only if there is a shared discussion amongst teachers who share cooperatively their divergent thoughts and opinions regarding teaching and learning activities. 
Teachers, similar to any other adult learners, have egos as rightly stated by [16], so they do not just commit themselves so easily. This is to lessen the fright of being judged in the course of learning activities. Hence, through collegial dialogue, teachers feel safe and their level of trust tends to develop and gradually, they have trust and positive working relationships with their colleagues. They feel free to share their teaching methodologies issues, and other teaching and learning challenges they are faced with. In [17], it is claimed that for professional learning communities to be operational, the collegial dialogue among teachers must assume a stage of individual poise and belief. This will in turn bring out the willingness, honesty, and transparency in teachers to evaluate their own activities and opinions.

In [18], it is revealed that collective trust in the midst of teachers was the robust initiator of professional community. Thus, they recommend that such trust could be crucial for a proficient community to emerge. However, functioning and reflecting collectively can form trust and at the same time strengthen relationships. The authors of [19] in their study on teacher clusters in South Africa reveal that the existence of a teacher cluster cannot provide the prospect for effective professional development of a teacher. They further found that it is collaborations between teachers in the clusters through connections of belief and personality that actually make the cluster to be a strategy for varying teachers' professional understanding and practice. Thus, there is a need for trust and positive relationships among teachers to expand their professional development. Hence, this current study seeks to find out how trust and positive working relationships amongst teachers in communities of practice are helping them as an avenue for professional development.

\section{Research Question}

The main research question guiding this study was how trust and positive working relationships among teachers in communities of practice are an avenue for professional development? The study was further guided by the following sub-research questions:

- What form of trust and working relationships exist within group members?

- What do teachers do to confirm there is trust and good relationships among them in communities of practice?

- How are group members feeling safe to be part of communities of practice?

- What are the reasons for feeling safe in communities of practice?

- What was learnt from the interactions by working collectively with group members in communities of practice?

- How teachers have improved by working together or interacting with group members in communities of practice?

\section{Materials and Methods}

\subsection{Research Methodology}

This study employed the mixed methods research approach in order to get a broader and deeper understanding of participants on trust and positive working relationships among teachers in communities of practice as an avenue for professional development [20]. The research approach assisted the researchers to have useful and in-depth information on the level of trust and positive working relationships among teachers in their various schools' communities of practice. Moreover, using the mixed methods approach it was ensured that the biases that might occur using a single method will be neutralised by using other methods [21]. Hence, a concurrent triangulation research design was employed, this helped collect both qualitative and quantitative data concurrently and mix the data in the explanation of the overall results [21]. Thus, in this study, face-to-face interviews were conducted and questionnaires were administered at the same time, qualitative data were used to triangulate the quantitative data and quantitative data were used to triangulate qualitative data, hence, the information complemented each other during the data analysis and explanation process and gave 
a holistic picture of the trust and positive relationships among teachers in communities of practice towards their professional development.

\subsection{Sample and Sampling Technique}

Ten high schools were selected out of the forty-eight schools within the six clusters in Fort Beaufort Education District. Balanced sampling, which is also known as sampling proportional to size, was used because all the high schools in the district were involved in either formal or informal communities of practice. The authors of [22] note that the balanced sampling technique includes choosing the components in a manner that, with respect to certain variables, the mean of the sample is close to the mean of the population. A total number of seventy-nine participants, which consisted of a principal, teacher, head of department (HoD), cluster leader, subject advisor, and education district official were selected for this study. The purposive sampling technique was used to select samples for qualitative data due to their understanding and information about the phenomena under study. This was employed as it enabled the researchers to select participants with expedient information [23]. Hence, fifteen participants were selected as samples for qualitative data, which consisted of teachers, heads of departments (HoDs), cluster leaders, subject advisors, and education district officials. Stratified random sampling, which is also known as optimum allocation stratified sampling as stated by [24], was used to select quantitative data. This sampling technique was employed to address the difficulty of a nonhomogeneous population because it attempts to represent the population rather than using simple sampling. Thus, sixty-four participants, which include teachers, principals, HoDs, and cluster leaders were selected as samples for quantitative data.

\subsection{Data Collection Instruments and Procedure}

Face-to-face interviews and semi-structured questionnaires were used as research instruments for this study. Semi-structured interviews were used because they have the features of structured and unstructured interviews and thus use both closed and open-ended questions and have the advantages of both methods of interview. The researchers have questions that they have prepared in the form of interview guides for all the participants. The questions were prepared in order to be consistent when asking the participants questions. Moreover, the interview guides assisted the researchers to ask the interviewees the relevant questions in the areas of phenomenon under study. During the interviews, the participants had the opportunities to give detailed information on each question and the researchers were able to probe further when necessary to get adequate information from the participants. All the interviews schedule the researchers had with the participants were recorded with a voice recorder, while some notes were also taken during the interview sessions to complement the recorded responses of the participants. However, permission was taken from the participants before the commencement of the interviews and recording of their voices for the purpose of this study [25].

In addition, semi-structured questionnaires with open-ended and closed questions were used to get expedient information and views of the participants on trust and working relationships amongst teachers in communities of practice. The questionnaires were self-administered by the researchers to sixty-four participants chosen for qualitative data. The questionnaires had an introductory part, where the title of the study was stated and the research study was briefly introduced to enable the respondents to understand what the study was all about. The questionnaires had two parts, the first of which was section A, which showed the socio-demographic characteristics of the participants and these included their age; sex; academic qualification; years of experience; and teaching subject. The second part was structured based on the sub-research questions and questions were asked based on each sub-research question.

\subsection{Data Analysis}

Qualitative and quantitative data collected were analyzed qualitatively and descriptively. The aim of the analysis of qualitative data is to determine patterns, concepts, themes, and meanings. In [26], 
qualitative data analysis is defined as a process of working with the data, organizing, breaking them into adaptable units, coding, synthesizing, and looking for emerging patterns. The qualitative data were classified and arranged in groups based on common features. The qualitative data were coded by assigning code words to each text based on the questions asked. The codes were later merged into themes and categories so as to make it easier for the researcher to come up with the emerging theme for each response of the question asked. Quantitative data were analyzed descriptively. Responses from the questionnaires were coded and entered using the statistical package for social science with a few analytical procedures to sum up the indicators. The analysis was done in the form of univariate analysis such as frequency counts and percentages [21].

\subsection{Ethical Considerations}

This study put ethical requirements into consideration. The researchers obtained permission from the department of education to have an official permission to collect data from chosen schools. Moreover, authorization to collect data were requested from the all the principals of selected schools before going to the sampled schools. Furthermore, the participants were given consent forms to sign to show their willingness and voluntary participation in this study and they were told they have the right to opt out at any stage if they feel like. Pseudo names were used for all the participants in order to protect their identities, thus, anonymity and confidentiality were observed in this study.

\section{Results}

The study tries to find out how trust and positive working relationships among teachers in communities of practice are an avenue for professional development. The study gives adequate information on this by responding to sub-research questions. Pseudo names were used for all the participants in order to protect their identity, thus, T1-T3, P1-P3, Clus1-Clus3, HD1-HD3, Sd1-Sd2, and Edu were used for participants who were teachers, principals, cluster leaders, heads of departments, subject advisors, and education district officials.

\subsection{Trust and Working Relationships with Group Members}

Trust and positive relationships are essential in communities of practice as they are main conditions for productive relationships [17]. Trust and positive relationships enable teachers to be free with each other to the extent that they will be able to share their problems in terms of classroom management and methodologies with their colleagues. The study sought to find out whether there is trust and positive working relationships amongst teachers in the communities of practice. The responses are presented in Table 1 below.

Table 1. Trust and working relationships with group members.

\begin{tabular}{ccc}
\hline $\begin{array}{c}\text { Whether There is Trust and Good Working Relationships among } \\
\text { Teachers in the Communities of Practice }\end{array}$ & Frequency & Percentage \\
\hline Yes & 61 & 95.31 \\
No & 3 & 4.69 \\
Total & 64 & 100.00 \\
\hline
\end{tabular}

Table 1 above shows that the majority of the participants (95.31\%) agreed that there is trust and good working relationships among group members to the extent that they share their classroom challenges with them, while only three $(4.69 \%)$ responded no to the question, which means to them that there is no trust and good working relationships among teachers in communities of practice. 
3.2. What Teachers Do to Confirm There Is Trust and Good Relationships among Them in the Communities of Practice

Table 2 below shows the data on what teachers do to confirm there is trust and good relationships among teachers in formal and informal communities of practice.

Table 2. What teachers do to confirm there is trust and good relationships among them in the communities of practice.

\begin{tabular}{ccc}
\hline $\begin{array}{c}\text { What Teachers do to Confirm There is Trust and Good Relationships } \\
\text { among Them in the Communities of Practice }\end{array}$ & Frequency & Percentage \\
\hline Willingness to assist others & 17 & 26.56 \\
Supporting group members & 22 & 34.38 \\
Confiding in their colleagues & 11 & 17.19 \\
Encouraging each other & 14 & 21.87 \\
Total & 64 & 100.00 \\
\hline
\end{tabular}

Table 2 above reveals that 17 (26.56\%) participants showed willingness to assist others, $22(34.38 \%)$ support group members, 11 (17.19\%) confide in their colleagues while 14 (21.87\%) encourage each other as part of what teachers do to confirm that there is trust and good relationships among them in formal and informal communities of practice.

In order to get more information on trust and working relationships among teachers in communities of practice, the participants they interviewed were asked how they feel about discussing their challenges in teaching methodologies with group members. Responses from teachers show that most of them are free with other group members since they work as a team and they share their problems with one another. The following are their responses:

It is always very easy because we share. You know where one has strength in some areas, while some are lacking in some aspects. So, we see it as a way of supporting each other in our school and with other schools. We support each other in areas we need help and assistance (T1).

I feel very good and comfortable because I know at least one of the group members will be able to help me in my school. Sometimes, I share my problems with some teachers in the cluster meeting because I know they are good and I know they have assisted some of my colleagues when they had similar problem (T2).

The heads of departments also gave the following comments in the same regard:

When you know this is my group, you feel safe with your group. You do everything possible to protect the interest of your group. I feel absolutely free discussing my teaching methodologies challenges with group members in this school since I know they are willingly to help and assist me, so why should I hide problems from them. I feel fulfilled sharing my problems with them (HD1).

I feel good because I know if I share my challenges with others they are willing to assist me, so why should I pretend that I know something when I did not know it. I relate well with my colleagues here in the school and if we go to other schools (HD2).

Cluster leaders interviewed were asked how teachers in their cluster feel about discussing their challenges in teaching methodologies with group members, they also agreed with the responses the teachers and heads of departments gave that teachers share their challenges with their colleagues.

I encourage them not to hide their problems with themselves. So mostly, they discuss their problems and share it with other group members (Clus1).

Since we work together as a team, they feel so good to discuss whatever teaching methodologies challenges they encountered or facing. We address such issues together as a group in the cluster meeting (Clus2). 
I will say they feel comfortable knowing fully well that group members will be of an assistance to them and this is a meeting of teachers from various schools within the cluster (Clus3).

Still on the same subject, the school principals interviewed were asked how teachers feel about discussing their challenges in teaching methodologies with them as school principals. They said teachers feel so comfortable with their colleagues in discussing any difficulty they faced in terms of their classroom management or teaching methodologies. According to them, teachers see it as their duties to relate with other members of the group. Their comments are as follows:

Teachers are very comfortable in discussing their teaching methodologies and content knowledge with regards to those challenges they have. The approach that no one should criticize the other has helped a lot in this regard in our school because they are willing now. Instead of making mockery of other teachers especially with the issue of teaching challenges, they themselves begin to suggest ways and how those teaching methodologies challenges can be solved (P1).

They feel very contented because I encourage them to share their problems among themselves and with me as some will be of help in the school and sometimes we get assistance from colleagues in other schools. If it is something beyond the teachers within the school or other schools, such matter is then referred to district official to see how they can help us (P3).

In order to get more information on this subject, the district officials were not left out in the interviews. They were asked how teachers feel about discussing their challenges in teaching methodologies with them. The comments they gave show that teachers feel comfortable and they are willing to disclose their problems with them and they know they can only get help from them when they reveal whatever challenges they are having in their methodologies. Their comments are as follows:

You know it is quite interesting because they are comfortable. Most of our educators especially at the Further Education and Training (FET) assist each other because there is an incentive in teaching grade 12, at the end of the year they want mark. When there is a mark, there is remuneration. So they want to acquire more knowledge as possible. So, they want to be rectified if they are using old fashioned teaching methodologies (Sd1).

As I have mentioned teachers are different. Others will just come clean especially those ones that are really desperate of assistance. They will tell you exactly at times they do understand the content of the subject but how to deliver it is the problem. Others are just hiding; they seem to be master of everything. Even how to get them, it is for the subject advisor to visit especially when the challenge is evident because when learners are not performing well it is an indicator that there is a challenge, you have to do something. So, as the subject advisor, you need to visit schools and see how teachers demonstrate and teach their learners and you have to demonstrate for them if there is a need to do so for the teacher in front of the learners... (Sd2).

Teachers feel good to share their challenges with me when they come for cluster meeting or when I go for school visit, I will not chastise them for doing so, rather we will see to it on how to help ourselves because our aim is to improve and assist all teachers to develop and in turn have positive effects on their learners $(\boldsymbol{E} d u)$.

Responses from the participants show that teachers assist each other, support themselves, encourage one another, and confide in their colleagues because of the relationships they have built over the years based on trust. It emerged that most of the participants revealed that working as a team enables them to freely share their teaching methodologies challenges with group members mostly in their schools and other schools. In the informal communities of practice, that is, communities of practice organized by teachers themselves at the school level to meet and assist each other, teachers see 
one another every day and they are free with each other, which make them more comfortable to share their problems. The findings of the study also reveal that in the formal cluster meeting, that is meetings that are organized by the department of education for teachers to meet and discuss on issues around their teaching and learning, some teachers hide their challenges as they do not want to be exposed in the presence of their colleagues from other schools. Therefore, it is essential for subject advisors to go to schools for classroom visits and see how teachers demonstrate and how to support them.

\subsection{Feeling Safe to Be a Part of the Communities of Practice}

The participants were asked to know if they feel safe to be a part of the formal and informal communities of practice in their various schools and with other schools. The responses are presented in Table 3 below.

Table 3. Feeling safe to be a part of the communities of practice.

\begin{tabular}{ccc}
\hline $\begin{array}{c}\text { Whether Respondents Feel Safe to be a Part of the } \\
\text { Communities of Practice }\end{array}$ & Frequency & Percentage \\
\hline Yes & 62 & 96.88 \\
No & 2 & 3.12 \\
Total & 64 & 100.00 \\
\hline
\end{tabular}

Responses from Table 3 above reveal that the majority of the participants (96.88\%) feel safe to be a part of the communities of practice while only two $(3.12 \%)$ do not feel safe to be among members in their school's communities of practice.

\subsection{Reasons for Feeling Safe in Communities of Practice}

Information were solicited from the participants to find out reasons for feeling safe in communities of practice with their colleagues. The data are presented in Table 4 below.

Table 4. Reasons for feeling safe in communities of practice.

\begin{tabular}{ccc}
\hline $\begin{array}{c}\text { Reasons Why Teachers Feel Safe with Their Colleagues in } \\
\text { Communities of Practice }\end{array}$ & Frequency & Percentage \\
\hline Assistance from colleagues & 9 & 14.06 \\
Closeness with group members & 15 & 23.44 \\
Friendly interaction & 13 & 20.31 \\
Advising and encouraging teachers & 12 & 18.75 \\
Comfortable atmosphere & 15 & 23.44 \\
Total & 64 & 100.00 \\
\hline
\end{tabular}

Table 4 above shows the reasons why the participants feel safe to be part of communities of practice in their schools and with other schools. The data reveal that nine $(14.06 \%)$ participants said they feel safe to be part of communities of practice because they get assistance from their colleagues, fifteen $(23.44 \%)$ participants said they feel safe because of their closeness with the group members, thirteen $(20.31 \%)$ participants indicated that they feel safe because they get advice and encouragement from their colleagues while the remaining fifteen $(23.44 \%)$ participants said the communities of practice activities within their schools and with other schools are conducted in a comfortable environment, which made them feel safe with other group members.

Comments from the interviews also revealed that, to a great extent, teachers feel safe with each other in communities of practice in their schools and at cluster levels and they freely share their teaching and classroom management challenges. Their comments are as follows:

I relate well with my colleagues in this school, whatever challenges I have relating to my subject,

I discuss with them because I feel safe with them and I get assistance from them (T2). 
When you relate as a group, there is a closeness which help you to feel safe to share your problems with your group members. Same thing is applicable here, we are free with teachers in our school and even in other schools. It is a helpful feeling which has resulted in good way of improving ourselves in our school work (T3).

We feel good and freely express ourselves with other colleagues in this school and with other schools, we share our problems and find a way to solve and assist each other since we are working as a group to develop each other professionally (HD2).

Mostly what we do in teachers meeting is that we make sure that we make all teachers comfortable and feel free, this will enable them to confide in each other the challenges they have relating to their work. And do you know what, it is really working, you will not belief different challenges teachers have that they are managing on their own but with this initiative, it has really helped them to improve and we are still improving since is a learning process and it is a continuous one (Clus2).

The principals, subject advisors, and education district officials interviewed were asked how teachers feel about discussing their teaching methodologies challenges, content knowledge, and curriculum with them. It was revealed that teachers feel free to discuss their challenges with them because they relate as colleagues and work as a group.

I relay well with all the teachers in the group, we see ourselves as one, this helped them to be free and discuss any problems they have with me and we make the environment comfortable for teachers to be free with each other (P3).

We started by seeing ourselves as friends whenever we meet for cluster meetings, we want improvement, we can only achieve this in a friendly environment. Even if I go for a classroom visit, we work together as one and this made them to discuss freely with me whatever issues they have (Sd2).

We encourage teachers and advise them to improve on their school work whenever we hold our meeting. If they notice and problem or have any issues, we advise they should discuss with any district official or their school heads. It is all about understanding each other and showing the willingness to help the group members in cluster meetings and in their various schools (Edu).

The findings of the study indicate that most teachers feel safe with their colleagues especially in the informal communities of practice within their various schools because of their closeness with their colleagues and assistance they get from them. Moreover, teachers also feel safe in formal communities of practice especially with the teacher whom they know very well and they trust them enough to confide in them whatever challenges they are facing. Some teachers also confide in the district officials because of the friendly relationship they have enjoyed from them.

3.5. What Was Learnt from the Interactions by Working Collectively with Group Members in Communities of Practice

The researchers sought to establish what was learnt from the interactions by working collectively with group members in communities of practice. The results are shown in Table 5 below.

Table 5. What was learnt from the interactions by working collectively with group members in communities of practice.

\begin{tabular}{ccc}
$\begin{array}{c}\text { Whether Respondents Learnt from the Interactions in the } \\
\text { Communities of Practice }\end{array}$ & Frequency & Percentage \\
\hline Yes & 61 & 95.31 \\
No & 3 & 4.69 \\
Total & 64 & 100.00 \\
\hline
\end{tabular}


Table 5 above shows that the majority of the participants (95.31\%) said as teachers, they have learnt from the interactions by working collectively with group members in communities of practice, only three (4.69\%) said they have not learnt from the interactions through working collectively with group members in formal and informal communities of practice.

\subsection{How Teachers Have Improved by Working Together or Interacting with Group Members in Communities of Practice}

The researchers further tried to find out how teachers have improved by working together or interacting with the group members in communities of practice. The results are shown in Table 6 below.

Table 6. How teachers have improved by working together or interacting with group members in communities of practice.

\begin{tabular}{ccc}
\hline $\begin{array}{c}\text { How Teachers Have Improved Through Working Together and } \\
\text { Interacting with Group Members in Communities of Practice }\end{array}$ & Frequency & Percentage \\
\hline Teachers learnt new skills from their colleagues in terms of classroom & 18 & 28.13 \\
management & 13 & 20.31 \\
Improvement on teaching methodologies & 9 & 14.06 \\
Improve strategies on handling learners in the classroom & 13 & 20.31 \\
New approaches to planning lessons & 11 & 17.19 \\
Improvement on teachers' content knowledge & 64 & 100.00 \\
Total & & \\
\hline
\end{tabular}

Table 6 above shows the results on how teachers have improved by working together or interacting in communities of practice. The data show that $18(28.13 \%)$ participants learnt new skills from their colleagues in terms of classroom management, 13 (20.31\%) respondents improved on their teaching methodologies, nine (14.06\%) participants improved on strategies of handling learners in the classroom, $13(20.31 \%)$ participants had new approaches to planning lessons, and $11(17.19 \%)$ respondents improved on their content knowledge.

Teachers were asked to explain things they have gained or acquired by working together or interacting with group members. The question was asked to get in-depth information on how teachers have improved by working as a team and interacting with their group members. Responses revealed that the majority of the teachers were able to improve on their teaching and learning methodologies while most were able to acquire new knowledge and skills, as well as classroom management.

Through my interactions with my group members, we worked as colleagues and this helped me to learn new ways of doing my work. For instance, I have been able to improve on my teaching methods and classroom management. I do not have difficulty in managing my classroom and coping with understanding the needs of my students and how to help them to improve in their studies (T2).

I have personally gained a lot of things. I have the patience to relate with other teachers. My attitude to my work has improved. I have learnt so many things from my colleagues to improve my teaching skills and this to me is a great achievement.

The information given by the heads of departments correlates with information given by the teachers. The heads of departments also alluded to the responses from the teachers. They have enjoyed working mutually with their group members, this mutual relationship has built their confidence, advanced their teaching methodologies, and how they manage their classes.

This program is helping many of us very well. Let me now speak about myself, this program has assisted me to discover my hidden talents and abilities. My teaching methodologies differ now, I switch to the one that I felt is suitable for my students to be able to give them the best and to manage the classroom activities (HD1). 
HD3 said that through joint efforts in their communities of practice, many members have learnt one or new things. You will see a new way of teaching that is commendable being introduced by your colleague and you will appreciate it by also trying the same. We are really helping each other and that is what working as a group meant, mainly to support one another.

Our meeting together is helping us as teachers. There are some things I do not know but others know very well, so what do we do, we assist each other. We support ourselves when we need help and this is working for us in this school. To me it is a good initiative towards our development professionally, we have learnt various new ways of doing our work and I know we will keep on learning in as much we do not cease to support one another (HD3).

Moreover, in order to get more insight in what various schools have gained through their engagement in working as groups as well as interacting with group members, the school principals were asked to describe what their schools have actually achieved through their engagement in communities of practice activities. Their responses are:

... our meetings worth it, let me start with that. Our time and efforts are not wasted, we are benefitting as professional in our field of interest. Teachers are doing well and are developing, we work hard to help ourselves to solve some challenges we have with our subjects, teaching activities and classroom management. We have identified all these challenges and we are trying our best to find solution to it. Teachers have trust in each other which made them to interact and learn new ideas of how to improve on their school work and content knowledge (P1).

We have achieved so many things together as teachers in this school and with other schools. We sometimes adopt exchange style where we allow some teachers from other schools to come and assist our students especially the senior classes. There are some topics that required extra help from other teachers, so we do that to assist both teachers and students (P2).

Cluster leaders were also asked to explain what high schools in their various clusters have gained and learnt by working together or interacting with their group members in the communities of practice in their schools or other schools. Their responses are in agreement with responses from other participants. They alleged that teachers get assistance and support in their engagement with other teachers, which has assisted development in their profession.

There are numerous ways this idea of meeting with other teachers has contributed to our teacher's development. Teachers are helped at the cluster level and many workshops are in place to support them in their teaching activities (Clus1).

I must let you know our teachers are trying their best, the engagement with their colleagues worth commending. New experiences are gained, you know when you share ideas with others, you interact and come with different views. Teachers are introducing new skills and you could see se reflection in their students' performance.

In addition, during the interviews conducted with district officials, the researchers tried to find out what high schools in the district have gained or learnt by working together or interacting with their group members in communities of practice. The information received from them are:

Absolutely, teachers have learnt a lot and gained new experiences with this program. This is because at the end each and every cluster meeting, they have an evaluation workshop form to fill to give feedback and suggestions. They always give good feedback that the learning activities are supportive and they are learning new things (Sd1).

It is obvious that our teachers in our schools are learning a lot through these meetings. When you interact with them, they will share their experience with you. There are support measures in place 
at the district level to assist teachers and get feedback from them. We are aware that they have some problems in certain aspects, that is the essence of the support measures. We follow up with them to assist. However, teachers are doing well with their meetings either in their school or with other schools. They support one another, share ideas, discuss their challenges and see how to find solution to such challenges without finding faults (Sd2).

When you see what teachers have achieved at district level by assisting and supporting themselves, you will see that this learning initiative worth it. They are introducing new strategies of teaching their students and improving on their teaching methodologies. Their meeting together as groups is assisting them in capacity building, good communication with colleagues and students and improving their skills as professionals $(\boldsymbol{E} \mathbf{d u})$.

It is evident from the information gathered from the participants that teachers have gained and learnt many things by their involvement in communities of practice in their schools and with other schools. Teachers supported each other, experiences and ideas were shared, teaching activities and classroom management were improved on. The responses of the participants also revealed that teachers interacted as colleagues and the support given to one another reflected in their students' performances, which means their students' academic performances improved. Teachers worked jointly and collectively in their group meetings and they see the need to assist themselves to build on their professional development, they believed in team work and this helped them gain new skills and improve on their teaching methodologies.

\section{Discussion}

For collaboration and effective learning to take place, it is evident that there is a need for regular communication and interaction with members in their communities of practice. This is very important in order to create positive relationships with members as well as building good and solid trust among them. If the level of trust is good, members will feel safe and this will help them to freely discuss whatever challenges they are having in various aspects of their work ranging from their teaching methodologies to classroom management [27-29]. The author of [30] notes that when we talk about the issue of trust and feeling safe, they are sensitive factors which must be treated with care as each member is sensitive to their emotions. Thus, once there are good interactions within the group members, they feel safe and have trust to open up, thus, identifying areas of difficulties for each member becomes easier and this will help in knowing the appropriate measures to support and assist them.

It is evident that a lack of trust among teachers in communities of practice will surely hinder positive working relationships as the teachers will not feel safe to be part of the group. The findings of this study reveal that most of the respondents trust and have good working relationships with group members most especially in informal communities of practice, and they share their classroom challenges with them as they get help and assistance from them. This arises from the fact that in informal communities of practices at the school level, teachers know each other and some form of relationship and trust already exists. This makes it easier for people to collaborate and open up to each other, work in teams because they feel safe, and are able to identify their weaknesses as they know they can be assisted and can also develop professionally.

The findings of this study are also in accordance with an argument made by [10] that trust and positive relationships are a system that assist collaborative learning activities in communities of practice. This is so because trust and positive relationships in communities of practice offer collective assets that enable teachers to have a mutual engagement, which the results have proved excellently better than working as an individual. The study also found that the support teachers get from their colleagues in communities of practice helped them feel safe and also brings confidence within the group members and this in turn made them enjoy responsive collaboration in an advantageous learning atmosphere. When the learning atmosphere is conducive and group members are committed and supportive, there 
will be freedom to express whatever challenges they have and trust would have been built over a period of time and there would be no fear, thus, members will have trust and positive working relationships.

It was also found from this study that what teachers do to confirm trust and good relationships in formal and informal communities of practice include being willing to assist others, supporting one another, confiding in their colleagues within the group, and encouraging one another. According to [16], adult learning has self-esteem involved; as a result, professional development must be designed to offer support by colleagues and to lessen the fear of judgment during learning. This implies that when teachers support themselves in communities of practice, good relationships will exist among group members and this will strengthen their level of trust for each other.

The findings of this study further revealed that most of the participants feel safe to be a part of the communities of practice. Moreover, findings of the study complement Speck's theory [16] as it is highlighted that adult learners have an ego, thus, they will not commit themselves anyhow to any learning programs, this is to reduce the fear of judgement during learning activities, thus, they feel safe when they are involved in collegial dialogue. The finding of the study also complements the literature reviewed, the authors of [13] claim that teachers will only open themselves up to learning and participation in learning communities' activities such as classroom observation, discussion about pedagogical issues, and curriculum innovation when they are confident and know it will be safe for them to do so.

However, the authors of [15] argue that shared collaboration is not sufficient to change the status quo in communities of practice. "The type of interaction that may influence knowledge creation and conceptual change includes collegial dialogue between teachers who openly share their differing opinions, values and views on teaching" [15] (p. 45). Shared discussion explores teaching and learning more deeply instead of friendly discussions, which is more on the surface and superficial. In order to be an operative shared discussion "assumes a level of personal confidence and trust which allows teachers to be willing, honest and transparent to review their own practices and beliefs" [31] (p. 284). In [32] (p. 175), the authors note that for this to transpire "a circle of inquiry is required on a particular topic in which they identify a shared vision for that aspect and then start identifying gaps in this vision and their current practice". The attained understanding should in turn be applied and information collected and analyzed to define the effect on learning [31]. According to [33], this is known as a transformative CPTD model. The model in this case consists of the Action Research model, which is a dominant instrument for change and enhancement at the local level [34] (p. 221). It includes teachers in research and the assessment of their own achievement. Action Research which is one of the models of CPTD has been recognized as being fruitful in enabling teachers to ask crucial questions regarding their practice [33].

Interaction and building relationships and ultimately collaboration and collective learning takes time and hence, it requires meeting regularly and for a longer duration. It was evident that the insufficient time allocated for communities of practice had its challenges. Time spent on communities of practice meetings is inadequate and as respondents said, most times they cannot cover everything that is planned for a session or meeting. Issues of meetings being held irregularly came from some of the respondents. This affects the level of collegial dialogue among teachers in communities of practice. It might not be possible to deal with issues in-depth but one is likely to end with what [31] called "congenial conversations".

\section{Conclusions}

It is evident that trust and positive relationships amongst teachers in communities of practice is a collective effort, thus, teachers need to engage in collaborative learning with mutual understanding and agreement. Joint efforts are required by teachers to work as teams and build their trust and working relationships over time, though this requires a joint and collective effort from teachers and support from the group members. The learning activities should be organized in a manner that teachers are free to relate with each other without any fear to help them support and assist their professional 
development. The learning environment should be made in a friendly manner, not tense, to enable teachers to freely share their ideas and relate very well with their colleagues.

\section{Recommendations}

Based on the findings of the study, the study recommends regular collaborative meetings for a longer duration for teachers in communities of practice to engage in collegial dialogue towards their teaching methodologies and classroom management. The amount of time allocated for meetings is imperative as it will enable them to have enough time to share their professional challenges with their colleagues and over time build trust and strong relationships with their colleagues to seek help that will contribute to their professional development. Moreover, collaborative learning activities in communities of practice in high schools should be made lively and not too formal for teachers to feel free to share their experiences with group members.

Author Contributions: Conceptualization, A.F.A.; methodology, A.F.A., S.R. and V.N.; formal analysis, A.F.A.; Investigation, A.F.A.; resources, A.F.A., S.R. and V.N.; writing-original draft preparation, A.F.A.; writing-review and editing, A.F.A., S.R. and V.N.; supervision, S.R. and V.N.; project administration, A.F.A., S.R. and V.N. All authors have read and agreed to the published version of the manuscript.

Funding: This research received no external funding And The APC was funded by [University of Fort Hare, South Africa].

Conflicts of Interest: The authors declare no conflict of interest.

\section{References}

1. Patton, K.; Parker, M. Teacher education communities of practice: More than a culture of collaboration. Teach. Teach. Educ. 2017, 67, 351-360. [CrossRef]

2. Windschitl, M.; Thompson, J.; Braaten, M.; Stroupe, D. Sharing a Vision, Sharing Practices: How Communities of Educators Improve Teaching. Remedial Spec. Educ. 2019, 40, 380-390. [CrossRef]

3. Desimone, L.M. Improving impact studies of teacher's professional development: Toward better conceptualizations and measures. Educ. Res. 2009, 38, 181-199. [CrossRef]

4. Maistry, S.M. Towards collaboration rather than cooperation for effective professional development of teachers in South Africa: From social practice theory. South. Afr. Rev. Educ. Educ. Prod. 2008, 12, 1-20.

5. Lee, H.L. Developing a professional development programme model based on teachers' needs. Prof. Educ. 2005, 27, 39-49.

6. Wenger, E.; McDermott, R.; Synder, W.H. Cultivating Communities of Practice: A Guide to Managing Knowledge; Harvard Business School Press: Boston, MA, USA, 2002.

7. Wenger, E. Communities of Practice: Learning, Meaning and Identity; Cambridge University Press: New York, NY, USA, 1998.

8. Lave, J.; Wenger, E. Situated Learning: Legitimate Peripheral Participation; Cambridge University Press: Cambridge, UK, 1991.

9. Mashologu, W.N. An Assessment of the Implementation of Continuing Professional Development Programmes for Teachers in Secondary Schools in Lady Frere District, Eastern Cape Province. Ph.D. Thesis, University of Fort Hare, Alice, South Africa, 2012.

10. Poultney, V. Professional Learning Communities and Teacher Enquiry; Critical Publishing: St. Albans, UK, 2020.

11. West-Burnham, J.; Otero, G. Educational Leadership and Social Capital; Incorporated Association of Registered Teachers of Incorporated Association of Registered Teachers of Victoria: Victoria, Australia, 2004.

12. Cohen, L.; Manion, L.; Morrison, K. Research Methods in Education; Routledge: London, UK, 2007; Volume 6.

13. Bolam, R.; McMahon, A.; Stoll, L.; Thomas, S.; Wallace, M.; Greenwood, A.; Smith, M. Creating and Sustaining Effective Professional Learning Communities; Department for Education and Skills: London, UK, 2005.

14. Nansubuga, F.; Munene, J.C.; Kikooma, J.; Nansamba, J.; Musanje, K. An effective learning culture: Using high performance work systems to strengthen the relationship between communities of practice and knowledge creation in Africa. Afr. J. Manag. 2019, 5, 162-181. [CrossRef]

15. Katz, S.; Earl, L. Learning about networked learning communities. Sch. Eff. Sch. Improv. 2010, $21,27-51$. [CrossRef] 
16. Speck, A. Adult Learning Theory; Pathways Home: North Wiley Central Regional Educational Laboratory; Columbia University: New York, NY, USA, 1996.

17. Katz, S.; Earl, A.; Jaafar, S.B.; Elgie, S.; Foster, L.; Halbert, J.; Kaser, L. The key enablers of successful knowledge communities. McGill J. Educ. 2008, 43, 111-137. [CrossRef]

18. Bond, M.A.; Blevins, S.J. Using Faculty Professional Development to Foster Organizational Change: A Social Learning Framework. TechTrends 2020, 64, 229-237. [CrossRef]

19. Jita, L.C.; Ndlalane, T.C. Teacher clusters in South Africa: Opportunities and constraints for teacher development and change. Perspect. Educ. 2009, 27, 58-68.

20. Turner, S.F.; Cardinal, L.B.; Burton, R.M. Research design for mixed methods: A triangulation-based framework and roadmap. Organ. Res. Methods 2017, 20, 243-267. [CrossRef]

21. Creswell, J.W. Research Design. Qualitative and Quantitative and Mixed Approaches, 4th ed.; SAGE: Thousand Oaks, CA, USA, 2014.

22. Kumar, R. Research Methodology: A Step-by-Step Guide for Beginners; SAGE: Thousand Oaks, CA, USA, 2019.

23. McMillan, J.C.; Schumacher, S. Research in Education: Evidence-Based Inquiry; Pearson/Allyn and Bacon: Boston, MA, USA, 2006.

24. Corbetta, P. Social Research: Theory, Methods and Techniques; SAGE: Thousand Oaks, CA, USA, 2003.

25. Maree, K. First Steps in Research; Van Schaik Publishers: Pretoria, South Africa, 2007.

26. Salmona, M.; Lieber, E.; Kaczynski, D. Qualitative and Mixed Methods Data Analysis Using Dedoose: A Practical Approach for Research across the Social Sciences; SAGE: Thousand Oaks, CA, USA, 2019.

27. Handelzalts, A. Collaborative curriculum development in teacher design teams. In Collaborative Curriculum Design for Sustainable Innovation and Teacher Learning; Pieters, J., Voogt, J., Pareja Roblin, N., Eds.; Springer: Cham, Switzerland, 2019; pp. 159-173.

28. Jita, L.C.; Mokhele, M.L. When teacher clusters work: Selected experiences of South African teachers with the cluster approach to professional development. South. Afr. Rev. Educ. Educ. Prod. 2014, 34, 1-15.

29. Pedder, D.; Opfer, V.D. Are we realising the full potential of teachers' professional learning in schools in England? Policy issues and recommendations from a national study. Prof. Dev. Educ. 2011, 37, 741-758. [CrossRef]

30. West, R.E. A Framework for defining and researching the boundaries of learning communities. In Proceedings of the Paper Presented at the Conference of the Association for Educational Communications and Technology in Anaheim, Anaheim, CA, USA, 23-27 October 2007.

31. Steyn, G.M. Building Professional Learning Communities to Enhance Continuing Professional Development in South Africa Schools. Anthropologist 2013, 15, 277-289. [CrossRef]

32. Nelson, T.H.; Deuel, A.; Slavit, D.; Kennedy, A. Leading deep conversations in collaborative inquiry groups. Clear. House 2010, 83, 175-179. [CrossRef]

33. Kennedy, A. Models of Continuing Professional Development: A framework for analysis. J. Serv. Educ. 2005, 31, 235-250. [CrossRef]

34. Church, M.; Bitel, M.; Armstrong, K.; Fernando, P.; Gould, H.; Joss, S.; Vouche, C. Participation, Relationships and Dynamic Change: New Thinking on Evaluating the Work of International Networks; University College: London, UK, 2002.

(C) 2020 by the authors. Licensee MDPI, Basel, Switzerland. This article is an open access article distributed under the terms and conditions of the Creative Commons Attribution (CC BY) license (http://creativecommons.org/licenses/by/4.0/). 